\title{
Quality of Life and its Determinants in Preschool Children with Down Syndrome
}

\author{
M.E. Weijerman ${ }^{1,2,{ }^{*}}$, P.E.M. van Schie ${ }^{3}$, M.J.M. Volman ${ }^{4}$, A.M. van Furth ${ }^{2}$ and \\ R.J.B.J. Gemke ${ }^{2}$ \\ ${ }^{1}$ Department of Pediatrics, Rijnland Ziekenhuis, Leiderdorp, The Netherlands \\ ${ }^{2}$ Department of Pediatrics, VU University Medical Center, Amsterdam, The Netherlands \\ ${ }^{3}$ Department of Physiotherapy, VU University Medical Center, Amsterdam, The Netherlands \\ ${ }^{4}$ Research Centre for Cognitive and Motor Abilities, Utrecht University, Utrecht, The Netherlands
}

\begin{abstract}
Objective: Children with Down syndrome (DS) show a delay in cognitive and motor development and have various concomitant health problems. We compared Health-Related Quality of Life (HRQoL) in preschool children with DS with a reference group, and investigated child-related factors (i.e., developmental quotient, adaptive function, health problems, problem behaviour), and maternal level of education on HRQoL.

Method: In a cohort of 55 children with DS, HRQoL was measured with the TNO-AZL preschool children Quality of Life Questionnaire (TAPQoL). Data from a reference group were used for comparison. Developmental Quotient (DQ) was assessed with the Bayley Scales of Infant Development II, adaptive function with the Pediatric Evaluation of Disability Inventory, health problems were derived from the medical file, and behavioural problems were measured with the Child Behaviour Checklist.

Results: Children with DS ( $N=55$; mean age 41.7 months) scored significantly lower on the TAPQoL domains lung and stomach problems, motor function and communication compared to the reference group. DQ had a significant negative correlation with the domains lung problems and liveliness. Children with DS with respiratory or gastro-intestinal problems showed significant lower scores on lung problems and communication. Problem behavior had a significant negative correlation with the domains sleeping, appetite and social function. A low level of maternal education correlated negatively with positive mood. Adaptive function and congenital heart defect (CHD) did not significantly correlate with HRQoL.

Conclusion: Preschool children with DS show a lower HRQoL on particular domains of functioning compared to a normative sample. HRQoL of children with $D S$ is correlated to $D Q$, respiratory and gastro-intestinal health problems, problem behaviour and maternal education, but not to $\mathrm{CHD}$ and adaptive function.
\end{abstract}

Keywords: Down syndrome, Quality of life, Developmental Preschool children, Children.

\section{INTRODUCTION}

Down syndrome (DS) is the most prevalent chromosomal cause of intellectual disability. It occurs worldwide in a range of 1 out of every 625-1000 births $[1,2]$. The syndrome results in higher risk for associated medical conditions, as well as cognitive, language, and behavioral problems. Health problems in young children with DS consist mainly of congenital heart defects (CHD), congenital anomalies of the gastrointestinal tract and respiratory problems. Recent decades have shown a significant improvement of mortality and morbidity, especially as a result of the successful early treatment of CHD [1-7]. Preventive health care programs have also contributed to the overall improved medical outcome [3-7]. Outcome assessments of children with a chronic disease that receive treatment should be focused more on health

*Address correspondence to this authors at the Department of Pediatrics, Rijnland Ziekenhuis, P.O. Box 4220, 2350 CC Leiderdorp, The Netherlands; Tel: +31-71-5828282; Fax: +31-71-5828558; E-mail: m.weijerman@rijnland.nl related quality of life (HRQoL) and well-being [8]. HRQoL is defined as health status in 12 domains weighted by the impact of the health status problems on well-being [8]. HRQoL can be described according to four domains: physical, social, emotional and cognitive functioning. Medical issues like $\mathrm{CHD}$, specific behavior problems, age and family context may play a role in $\mathrm{HRQoL}$ of children with DS.

A recent study on the HRQoL of 8-year-old children with DS revealed that their HRQoL was lower for the domains of motor functioning, autonomy, social functioning and cognitive functioning [9]. Knowledge about the HRQoL in younger children and the factors that might influence their HRQoL is lacking. To define the possible influences on HRQoL in young children with DS the delay in motor development is an important domain to study. In young children with DS this delay substantially affects functional performance most and is on average more affected than cognitive development $[10,11]$. The more challenging language development in children with DS play an important role in their 
cognition as well. Particularly the expressive language lags behind while the receptive language is usually mental age appropriate [12-14]. A specific behavior phenotype of DS emerges around 2 years of age as a result of the relative strengths in aspects of visual processing, receptive language and nonverbal social functioning and weaknesses in gross motor skills and expressive language skills. Furthermore motor milestones in children with DS follow a specific sequence in their performance, mainly caused by disturbances in the system of postural control and tone [12, 15-18]. Development of children with disabilities can also be influenced by the family context, the level of education of the parents is part of this [19].

Finally children with DS show a wide variation in functional performance and ability levels, regardless the extent of the delayed fine motor skills $[20,21]$.

Compared to normally developing controls, specific behavior patterns of DS consist of stubbornness, oppositionality, inattention, difficulties in concentrating and impulsivity [22]. Children with DS have overall a relative predictable behavior and a good mood as favorable qualities [12].

In the present study we investigated HRQoL in children with DS aged 1 to 5 years old, compared to typically developing children, as well as the relation with child-related factors, such as, developmental age, adaptive function, health problems, problem behavior, and maternal level of education.

\section{METHOD}

\section{Procedure}

The VU University Medical Center (VUmc) has a dedicated outpatient clinic for children with DS, which accepts children with DS referred by parents themselves, general practitioners, and pediatricians from within and outside the hospital.

Between 2005 and 2007 parents of all children with DS aged 12-60 months attending this VUmc outpatient clinic were asked to participate in this study. Inclusion criteria were a cytogenetic confirmed diagnosis DS and an age of $12-60$ months at the start. If the parents were not able to speak and understand Dutch was considered as exclusion criterion. The clinical examinations were performed as part of our standardized clinical routine preventive health care program for children with DS with approval of the parents [5-7].

\section{Ethical Considerations}

Under Dutch law, our study involving solely health related questionnaires sent to healthy adults (the parents of the children involved) and was waived submission for full consideration by the institutional review board.

Informed consent was given by the parents of the children with DS who participated.

\section{Measurements}

For assessment of quality of life, the Netherlands Organisation for Applied Scientific Research (TNOAZL) Preschool children Quality of Life (TAPQoL) form was used [8, 23]. This is a generic instrument consisting of 43 items, covering physical, social, cognitive and emotional functioning in preschool children aged 2 to 48 months. It measures parent's perception of HRQoL, defined as health status in 12 domains weighted by the impact of the health status problems on well-being (Figure 1). Lower scores

In the last three months, has your child been...

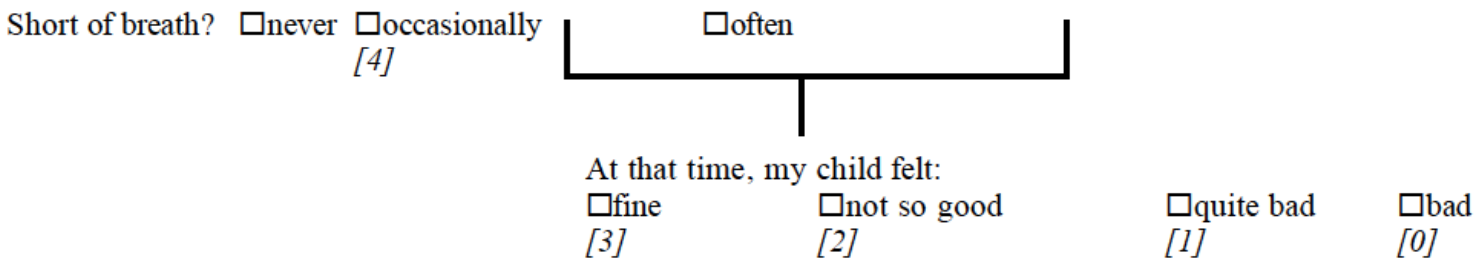

How was your child in the last three months?

In good spirits

$\square$ never $\square$ occasionally

$\square$ often

[2] [1]

[0]

Figure 1: Item example TAPQOL (the scores attributed to the paired items are in italics). Reprinted with permission of Fekkes et al. [8]. 
indicate a lower HRQoL. The reliability and discriminative validity of its scales for infants as well as toddlers has been reported satisfactory [8, 23]. All parents were sent this questionnaire by mail.

The results of the questionnaires of parents of a randomly selected general population sample of 318 children (192 boys, 56.5\%) aged 12-48 months (mean chronologic age 30.6 months, sd 11.0 months) were used as normative data, this is the reference group as stated previously by Bunge et al. [23].

Cognitive abilities were measured by the mental scale of the Bayley Scales of Infant Development, second version (BSID-II) [24]. The mental scale consists of 178 items. The raw scores of successfully completed items were converted to developmental age scores. Developmental Quotients (DQ) were calculated using the traditional mental age method (Mental Age/Chronological Age x 100).

Children's behavior was measured by the Child Behavior Checklist (CBCL) Parent Form either the CBCL 2-3 for children aged 2-3 years, or the CBCL 418 for children aged $4-18$ years. The CBCL is a questionnaire containing 113 items about childhood behavior problems [25]. Based on age- and genderdependent norm tables, the presence of externalizing problem behavior (delinquency, aggression) and internalizing problem behavior (depression, withdrawal and somatization) was assessed. The present study used the Dutch version of the CBCL, which has good psychometric properties, also in children with developmental delays [26, 27].

Adaptive function was assessed with the Dutch adaptation of the Pediatric Evaluation of Disability Inventory (PEDI). The PEDI is a standardized parent interview that examines adaptive function with regard to three domains: self-care, mobility, and social function [10]. All children with DS were followed up at the outpatient clinic for DS patients at the VU University medical center, the attending pediatrician (MW), who examined all the children at all visits according the international guidelines of children with DS [5-7]. The medical files were used for data collection. Maternal education was defined as less than high school, high school/general equivalency diploma and more than high school.

\section{Statistical Analysis}

Cronbach's a was used to determine the internal consistency of the TAPQoL scales. A one Sample t-test was applied to compare the TAPQoL domain scores of children with DS with the mean TAPQoL domain scores of the reference group [23].

Association between TAPQoL domain scores and chronological age and DQ was tested with Spearman's rho rank correlation coefficient. Partial correlation analysis was applied to test the relation between TAPQoL domain scores and PEDI domain scores with chronological age as control variable. A Mann-Whitney $U$ test was applied to test the differences between children with or without CHD, and children with or without respiratory and/or gastro-intestinal problems. A Kruskal-Wallis test was applied to test the effect of maternal education.

Analyses were carried out with SPSS version 16.0 (SPSS Inc., Chicago, IL, USA), level of significance was set at $\alpha=.05$.

\section{RESULTS}

In our study 98 children were eligible of which 55 finally participated. Response rate was $56 \%$ over the 3 years of data collection (2005-2007). The main reasons for not participating were lack of time $(n=31)$, illnesses of the child $(n=8)$ and some parents had forgotten their appointment $(n=4)$. The children who did participate were randomly distributed among the group of 98 children. The age distribution and characteristics of the participating children are shown in Table 1. Most children (87\%) were Dutch Caucasian. In 54 children the diagnosis DS was based on trisomy 21 and one had mosaicism. The mental age is almost half as would be expected according to the chronological age (mean 21.2 vs. 40.6 months respectively).

For the DS sample, Cronbach's a of the different TAPQoL scales ranged from 0.39 to 0.84 (Table 2). For most scales, the Cronbach's a was above 0.60 . However for the scales measuring stomach problems and skin problems, the Cronbach's a was low.

\section{Down Syndrome Group vs. Reference Group}

Table 2 shows the mean TAPQoL scores for DS and the reference group. Children with DS scored significantly lower on the domains lung problems $(\mathrm{t}=$ $3.34, p<.01)$, stomach problems $(\mathrm{t}=-2.17, p<.05)$, motor function $(\mathrm{t}=-8.73, p<.001)$, and communication $(\mathrm{t}=$ $12.99, p<.001)$ compared to the reference group, indicating a lower $\mathrm{HRQ}$ oL on these domains. No significant differences were found for sleeping, appetite, skin problems, social functioning, problem behavior, positive mood, anxiety, and liveliness. 
Table 1: Characteristics of Young Children with DS ( $N=55)$

\begin{tabular}{|c|c|}
\hline & DS children \\
\hline Mean Chronological Age in months (sd; range) & $40.6(12.8 ; 15-69)$ \\
\hline Male & $30(54.5 \%)$ \\
\hline Female & $25(45.5 \%)$ \\
\hline Mean BSID Mental Age (sd; range) & $21.2(6.7 ; 10-37)$ \\
\hline Mean BSID DQ (sd; range) & $53.8(10.1 ; 30-85)$ \\
\hline \multicolumn{2}{|l|}{ Adaptive function(sd) } \\
\hline Mean subscale PEDI Self care & $36.2(14.2)$ \\
\hline Congenital heart defect & $27(48 \%)$ \\
\hline Respiratory problems & $18(32 \%)$ \\
\hline Gastro-intestinal problems & $11(20 \%)$ \\
\hline \multicolumn{2}{|l|}{ Problem behavior $(N=30)$} \\
\hline Mean CBCL T-score (sd; range) & $52.8(7.8 ; 33-64)$ \\
\hline $\mathrm{CBCL}$ borderline/clinical range $(\mathrm{T} \geq 60)$ & $\mathrm{N}=6(20 \%)$ \\
\hline \multicolumn{2}{|l|}{ Maternal education } \\
\hline Less than high school & $4(7 \%)$ \\
\hline
\end{tabular}

Table 2: Score Distribution and Internal Consistency of TAPQOL Scores for the DS Group ( $N=55)$ and Reference Group $(\mathrm{N}=318)[23]$

\begin{tabular}{|c|c|c|c|c|c|c|c|c|}
\hline & \multicolumn{4}{|c|}{ DS } & \multicolumn{4}{c|}{ Reference } \\
\cline { 2 - 8 } & Mean (Sd) & Range & Median & $\alpha$ & Mean & Range & Median & $\alpha$ \\
\hline \hline Sleeping & $78.5(18.9)$ & $25-100$ & 75.0 & .72 & 78.6 & $13-100$ & 81.3 & .89 \\
\hline Appetite & $85.3(15.4)$ & $50-100$ & 91.7 & .76 & 81.9 & $33-100$ & 83.3 & .78 \\
\hline Lung problems & $82.4(22.8)^{\star *}$ & $17-100$ & 91.7 & .78 & 92.7 & $0-100$ & 100 & .82 \\
\hline Stomach problems & $87.3(15.8)^{*}$ & $50-100$ & 95.8 & .57 & 91.9 & $50-100$ & 100 & .53 \\
\hline Skin problems & $90.6(7.9)$ & $67-100$ & 91.7 & .39 & 91.0 & $17-100$ & 91.7 & .78 \\
\hline Motor function & $82.4(12.7)^{\star * *}$ & $25-100$ & 81.3 & .76 & 97.8 & $25-100$ & 100 & .89 \\
\hline Problem behavior & $73.9(20.3)$ & $14-100$ & 78.6 & .84 & 68.9 & $14-100$ & 71.4 & .78 \\
\hline Social function & $93.8(12.5)$ & $50-100$ & 100 & .81 & 91.8 & $33-100$ & 100 & .69 \\
\hline Communication & $68.4(11.6)^{\star * *}$ & $19-88$ & 68.8 & .72 & 89.4 & $31-100$ & 93.8 & .81 \\
\hline Positive mood & $98.5(6.3)$ & $67-100$ & 100 & .64 & 97.7 & $0-100$ & 100 & .91 \\
\hline Anxiety & $78.2(19.2)$ & $33-100$ & 66.8 & .68 & 75.8 & $0-100$ & 83.3 & .63 \\
\hline Liveliness & $96.1(11.1)$ & $50-100$ & 100 & .69 & 96.1 & $0-100$ & 100 & .80 \\
\hline
\end{tabular}

Note. $\alpha=$ Cronbach alfa.

${ }^{*} \mathrm{p}<.05,{ }^{* *} \mathrm{p}<.01,{ }^{* * \star} \mathrm{p}<.001$ measured by a one Sample t-test.

†Average Cronbach alfa for the 12 scales in the DS group was .77. 


\section{Effect of Chronological Age and Developmental Quotient (DQ) on TAPQol}

Table 3 shows a significant positive correlation between chronological age $(\mathrm{CA})$ and the TAPQoL motor function score $\left(r_{s}=.50, p<.001\right)$, indicating that older children with DS showed a higher score for that domain. A significant negative correlation between $\mathrm{CA}$ and the TAPQoL communication score was found $\left(r_{s}=-\right.$ $.30, p<.05)$, indicating that older children had lower scores on communication.

Table 3: Correlations between TAPQoL Domain Scores and Chronological Age (CA) and Developmental Quotient (DQ)

\begin{tabular}{|c|c|c|}
\hline TAPQOL scales & $\begin{array}{c}\text { CA } \\
\mathbf{r}_{\mathbf{s}}\end{array}$ & $\begin{array}{c}\text { DQ } \\
\mathbf{r}_{\mathbf{s}}\end{array}$ \\
\hline \hline Sleeping & .18 & .13 \\
\hline Appetite & -.14 & .14 \\
\hline Lung problems & -.06 & $.30^{*}$ \\
\hline Stomach problems & -.23 & .15 \\
\hline Skin problems & .16 & -.07 \\
\hline Motor function & $.50^{* *}$ & .16 \\
\hline Problem behavior & -.09 & .16 \\
\hline Social function & -.03 & .22 \\
\hline Communication & $-.30^{*}$ & .26 \\
\hline Positive mood & -.05 & .13 \\
\hline Anxiety & -.04 & .02 \\
\hline Liveliness & -.20 & $.41^{* *}$ \\
\hline
\end{tabular}

Note. ${ }^{*} p<.05,{ }^{* *} p<.01 . \mathbf{r}_{\mathrm{s}}=$ spearman's rho rank. correlation coefficient.

Correlation analysis of TAPQoL domain scores with BISD II DQ scores revealed significant positive correlations for lung problems and liveliness $\left(r_{s}=.30\right.$, $p<.05, r_{s}=.41, p<.01$, respectively) indicating that children with a lower $D Q$ (i.e. a larger mental developmental delay) had lower scores on these quality of life scales (Table 3). For communication a nearly significant effect was found $\left(r_{s}=.26, p=.07\right)$, indicating a trend for a lower HRQoL for the children with less communication abilities.

\section{Effect of Adaptive Function on TAPQol}

The mean scores on the PEDI domains self-care, mobility and social function are presented in Table 1. Partial correlation analysis (controlled for CA) did not reveal any significant relations between PEDI self-care, ambulation and social function scores and the different TAPQoL domain scores.

\section{Effect of Medical Conditions on TAPQol}

No significant differences on TAPQoL scores were found between children with or without CHD. All the CHD's had been corrected surgically when needed and at the time of the survey, hemodynamically important cardiac defects were no longer present in any of these children. The group children with DS with respiratory or gastro-intestinal problems scored significantly lower on the TAPQoL domains lung problems and communication compared to children without respiratory or gastro-intestinal problems (respectively, $Z=2.31, p<.05 ; Z=2.31, p<.05$; Table 4), while there was a trend in the same direction for the domain anxiety $(Z=1.83, p=.07)$. Both groups did not significantly differ in CA. All children had normal vision and hearing functions, no serious defects were seen.

\section{Effect of Problem Behavior on TAPQol}

Significant correlations were found between TAPQoL and CBCL scores $(\mathrm{N}=30)$ for the TAPQoL domains sleeping $\left(r_{\mathrm{s}}=-.42, p<.05\right)$, appetite $\left(r_{\mathrm{s}}=-.40\right.$, $p<.05)$, social function $\left(r_{s}=-.37, p<.05\right)$ and communication $\left(r_{\mathrm{s}}=-.46, p<.05\right)$. Children with higher scores on problem behavior had lower scores on these TAPQoL scales.

\section{Effect of Maternal Education on TAPQol}

A significant effect of maternal education on the TAPQoL domain positive mood was found (Chi square $=16.1, p<.001$ ), indicating a lower HRQoL score for the low education group $(M=87.5)$ compared to the middle and high education group (respectively, $M=100$; $M=99.1$ ).

\section{DISCUSSION}

This study provides an insight into the HRQoL of 55 preschool children with DS and shows the correlation with child-related (developmental quotient, functional status, health problems, problem behavior) and familyrelated (maternal education) factors. We compared the HRQoL with a normative reference group as well. In comparison with the reference group, children with DS showed a lower HRQoL on the domain of lung and stomach problems, motor function and communication. The HRQoL domains in children with DS were particularly affected by their developmental quotient, health problems (i.e. respiratory or gastro-intestinal), problem behavior, and maternal education. HRQoL in children with DS did not show a correlation with their 
Table 4: TAPQOL Scales for the DS Group with and without Respiratory or Gastro-Intestinal Problems

\begin{tabular}{|c|c|c|c|c|}
\hline \multirow[t]{2}{*}{ TAPQOL Scales } & \multicolumn{2}{|c|}{$\begin{array}{c}\text { Respiratory and/or } \\
\text { Gastro-Intestinal Problems } \\
\qquad(\mathrm{N}=24)\end{array}$} & \multicolumn{2}{|c|}{$\begin{array}{c}\text { No Respiratory or } \\
\text { Gastro-Intestinal Problems } \\
\qquad(\mathrm{N}=31)\end{array}$} \\
\hline & Mean & $S D$ & Mean & $S D$ \\
\hline Sleeping & 76.0 & 21.0 & 80.4 & 17.2 \\
\hline Appetite & 82.3 & 16.4 & 87.6 & 14.4 \\
\hline Lung problems & $74.6^{*}$ & 25.0 & 88.4 & 19.3 \\
\hline Stomach problems & 84.7 & 17.3 & 89.2 & 14.5 \\
\hline Skin problems & 92.0 & 8.7 & 89.5 & 7.2 \\
\hline Motor function & 83.9 & 11.8 & 81.2 & 13.5 \\
\hline Problem behavior & 69.6 & 21.8 & 77.2 & 18.7 \\
\hline Social function & 91.0 & 13.9 & 96.3 & 13.8 \\
\hline Communication & $64.6^{*}$ & 10.0 & 71.8 & 11.9 \\
\hline Positive mood & 98.6 & 6.8 & 98.4 & 6.6 \\
\hline Anxiety & 72.9 & 19.3 & 82.3 & 18.2 \\
\hline Liveliness & 95.8 & 2.5 & 96.2 & 10.2 \\
\hline
\end{tabular}

${ }^{*} p<.05$ measured by a Mann-Whitney $\mathrm{U}$ test.

adaptive function, and was not affected by the presence of a congenital heart defect.

Children with DS with more mental developmental delay (lower DQ scores) showed a lower HRQoL for lung problems and liveliness, and a trend toward significance for communication.

Recently HRQoL is investigated in a population sample of Dutch eight-year-old children with DS measured with the TACQoL [9]. Children with DS had significantly lower HRQoL scores for the scales gross motor skills, autonomy, social functioning and cognitive functioning compared to a normative sample [9]. Although the scales of the TACQoL are slightly different from those of the TAPQoL, the findings reported comparable with our findings, except for social functioning. Contrary to this study, we did not find a lower HRQoL for social functioning in our sample of young children with DS. That study also reported a developmental delay in cognitive function and more problem behavior in children with DS, however, the association between the individual differences in developmental delay and the observed level of HRQoL was not reported [9].

In our study CHD did not correlate with HRQoL. $\mathrm{CHD}$ in children with DS was considered to be the most relevant to morbidity and decisive in infant mortality. However over recent decades, there has been a substantial increase in the life expectancy of children with DS. The minor role of CHD in morbidity in children with DS has mainly been due to the successful early surgical treatment of the CHD of these children and could be responsible for the favorable HRQoL results in our study $[2,28]$. Children with DS scored significantly lower on the domain lung problems compared to the reference group, indicating a lower HRQoL on this domain.

One third of children with DS were reported to have difficulties with breathing or have other Respiratory problems [29]. Both wheeze ever, wheeze during the last 12 months and recurrent wheeze were more commonly reported in DS than in their siblings or controls [29, 30]. Respiratory problems are the most common reason for children with DS to be admitted and causes the excess in mortality [31,32]. In a recent study of Verstegen et al., 8-year-old children with DS with parent-reported recurrent respiratory tract infections (RRTI) showed more delayed development, behavioral problems and had a lower HRQoL compared with children with DS without RRTI [33]. The lower lung related scores found in our study underscore the importance of appropriate treatment and follow up of lung problems. Asthma and allergy do not seem to play an important role in this respect [30].

In our study we explored problem behavior and found a significant correlation between problem behavior and the TAPQoL domains sleeping, appetite, 
social function and communication. Unexpectedly this was not found on the TAPQol domain problem behavior. In our study $20 \%$ of the children with DS had $\mathrm{CBCL}$ borderline/clinical range ( $T$-score $>60)$, which is lower but comparable with the $27 \%$ found in the study of van Gameren et al., in 8 year old children with DS [9, 25]. Eisenhower et al. found in children with DS at age 3 , an age comparable with the children in our study, only $8 \%$ in the borderline/clinical range [33]. The problem behavior in children with DS ranked lowest among the groups of children with development delay, like autism and even showed fewer problem behavior than typically developing children. The behavior problems in children with DS described in this study increased over time up to age 5 , while typically developed children showed a decrease in total $T$ scores in time [34]. These results demonstrate that children with DS have more behavior problems when they get older and this may be the result of the increased expression of their externalizing behavior, like stubbornness [22, 32]. In our study the problem behavior had already a correlation with the HRQoL at the preschool age period.

In the present study we did not find any significant correlations of adaptive function (PEDI self-care, PEDI ambulation and PEDI social function scores) with HRQoL of children with DS, comparing different TAPQoL domain scores. In a study of 5 year old children with DS, Dolva et al. found a disadvantage of self care activities in those children with delayed fine motor skills [20]. Furthermore the children with DS appeared to be less affected in their functional mobility skills. In our study we did not find a correlation of mobility on the TAPQoL and motor function. Studies up to now report a variation in ability levels in children with DS. The children in our study population were relative young, as a result the differences and their functional performance could be less pronounced because of this age [20].

Finally we studied the education level of the mothers of the children with DS. Mothers from the low level education group reported a lower HRQoL for positive mood compared to the middle and high education group. Studies of typically developing children show the impact of aspects of families in promoting children's functioning and this may help to predict the development of children with disabilities. Hauser et al. found a significant positive correlation with mother's education level and growth in socialization domains [19]. On average, higher maternal education was associated with better developmental (HRQoL) perspectives for their child with DS [19]. The family environment composite can be important in this matter and may be a significant determinant of growth in three domains: communication, daily living, and social skills [19]. The HRQoL domain mood in our study had a negative correlation, when the mothers had a lower education level. These mothers may have more problems with coping and as such have lower well being and positive mood, which influences their child with DS. At the same time having a child with DS may be a potential source of distress. The amount of care of the partner and the support from the environment play an important role in this matter [35]. The present study has several limitations. Especially the small sample size of 55 children and the relative young age of the group children. The HRQoL information has been collected by proxy and may be influenced by the mood of the reporting parent $[34,35]$. Also we cannot exclude that the response rate may have introduced a selection bias. Although the most important results show significant differences our results should be interpreted with caution. Compared to $10-20$ years ago these children had substantial limited life expectancy and a different morbidity spectrum. The current improvement of the medical issues obliges us to look into new medical issues and new opportunities for these children regarding long term developmental outcome and HRQoL.

\section{CONCLUSION}

Preschool children with DS show a lower HRQoL on particular domains of functioning compared to a normative sample. HRQoL of children with DS is correlated to $\mathrm{DQ}$, respiratory and gastro-intestinal health problems, problem behaviour and maternal education, but not to CHD and adaptive function.

\section{CONFLICTS OF INTEREST}

There are no conflicts of interest

\section{WHAT'S KNOWN}

Recent decades showed a significant improvement of mortality and morbidity in children with Down syndrome (DS). The substantial increase in life expectancy in DS, due mainly to the successful early treatment of congenital heart disease, caused a change in morbidity. Research in children with DS has focused on the medical issues and moves into Health Related Quality of Life (HRQoL) issues. 


\section{WHAT'S ADDED}

A lower HRQoL in the children with DS is correlated with developmental quotient, respiratory and gastrointestinal problems, problem behaviour and maternal education, but not with a CHD and adaptive function.

\section{REFERENCES}

[1] Shin M, Besser LM, Kucik JE, et al. Prevalence of Down syndrome among children and adolescents in 10 regions of the United States. Pediatrics 2009; 124: 1565-71. http://dx.doi.org/10.1542/peds.2009-0745

[2] Weijerman ME, van Furth AM, Vonk NA, van Wouwe JP, Broers CJ, Gemke RJ. Prevalence, neonatal characteristics, and first-year mortality of Down syndrome: a national study. J Pediatr 2008; 152: 15-9. http://dx.doi.org/10.1016/j.jpeds.2007.09.045

Capone G, Goyal P, Ares W, Lannigan E. Neurobehavioral disorders in children, adolescents, and young adults with Down syndrome. Am J Med Genet C Semin Med Genet 2006; 142C: 158-72. http://dx.doi.org/10.1002/ajmg.c.30097

[4] Thomas K, Bourke J, Girdler S, Bebbington A, Jacoby P, Leonard $\mathrm{H}$. Variation over time in medical conditions and health service utilization of children with Down syndrome. J Pediatr 2011; 158: 194-200 e1.

[5] Roizen NJ, Patterson D. Down's syndrome. Lancet 2003; 361: 1281-9. http://dx.doi.org/10.1016/S0140-6736(03)12987-X

[6] American Academy of Pediatrics. Committee on Genetics. American Academy of Pediatrics: Health supervision for children with Down syndrome. Pediatrics 2001; 107: 442-9. http://dx.doi.org/10.1542/peds.107.2.442

[7] Weijerman ME, Winter de JP. Clinical practice the care of children with Down syndrome. Eur J Pediatr 2010; 169: 1445-52. http://dx.doi.org/10.1007/s00431-010-1253-0

[8] Fekkes M, Theunissen NC, Brugman E, et al. Development and psychometric evaluation of the TAPQOL: a healthrelated quality of life instrument for 1-5-year-old children. Qual Life Res 2000; 9: 961-72. http://dx.doi.org/10.1023/A:1008981603178

[9] Gameren-Oosterom van HB, Fekkes M, Buitendijk SE, Mohangoo AD, Bruil J, Van Wouwe JP. Development, problem behavior, and quality of life in a population based sample of eight-year-old children with Down syndrome. Plos One 2011; 6: e21879. http://dx.doi.org/10.1371/journal.pone.0021879

[10] Pueschel SM, Gallagher PL, Zartler AS, Pezzullo JC. Cognitive and learning processes in children with Down syndrome. Res Develop Disabil 1987; 8: 21-37. http://dx.doi.org/10.1016/0891-4222(87)90038-2

[11] Volman MJM, Visser JJW, Lensvelt-Mulders GJL. Functional status in 5 to 7 year old children with Down syndrome in relation to motor ability and performance mental ability Disabil Rehabil 2007; 29: 25-31. http://dx.doi.org/10.1080/09638280600947617

[12] Fidler DJ. The emerging Down syndrome behavioral phenotype in early childhood. Implications for practice. Infants and Young Children 2005; 18: 86-103. http://dx.doi.org/10.1097/00001163-200504000-00003

[13] Silverman W. Down syndrome: cognitive phenotype. Ment Retard Dev Disabil Res Rev 2007; 13: 228-36. http://dx.doi.org/10.1002/mrdd.20156
Roberts JE, Price J, Malkin C. Language and communication development in Down syndrome. Ment Retard Dev Disabil Res Rev 2007; 13: 26-35. http://dx.doi.org/10.1002/mrdd.20136

[15] Vicari S. Motor development and neuropsychological patterns in persons with Down syndrome. Behav Genet 2006; 36: 355-64 http://dx.doi.org/10.1007/s10519-006-9057-8

[16] Lauteslager PEM, Vermeer A, Helders PJM. Disturbances in the motor behavior of children with Down's syndrome: the need for a theoretical framework. Physiotherapy 1998; 84: 514. http://dx.doi.org/10.1016/S0031-9406(05)65896-8

[17] Palisano RJ, Walter SD, Russell DJ, et al. Gross motor function of children with down syndrome: creation of motor growth curves. Arch Phys Med 2001; 82: 494-500. http://dx.doi.org/10.1053/apmr.2001.21956

[18] Chapman RS, Hesketh LJ. Behavioral phenotype of individuals with Down syndrome. Ment Retard Dev Disabil Res Rev 2000; 6: 84-95. http://dx.doi.org/10.1002/1098-2779(2000)6:2<84::AIDMRDD2>3.0.CO;2-P

[19] Hauser-Cram P, Warfield ME, Shonkoff P, Krauss MW Upshur CC, Sayer A. Family influences on adaptive development in young children with Down syndrome. Child Dev 1999; 70: 979-89. http://dx.doi.org/10.1111/1467-8624.00071

[20] Dolva AS, Coster W, Lilja M. Functional performance in children with Down syndrome. Am J Occupat Ther 2004; 58: 621-9.

http://dx.doi.org/10.5014/ajot.58.6.621

[21] Spano M, Mercuri E, Rando T, et al. Motor and perceptualmotor competence in children with Down syndrome: variation in performance with age. Eur $\mathrm{J}$ Paediatric Neurol 1999; 3: 7-14. http://dx.doi.org/10.1053/ejpn.1999.0173

[22] Dykens EM. Psychiatric and behavioral disorders in persons with Down syndrome. Ment Retard Dev Disabil Res Rev 2007; 13: 272-8.

http://dx.doi.org/10.1002/mrdd.20159

[23] Bunge EM, Essink-Bot ML, Kobussen MP, van SuijlekomSmit LW, Moll HA, Raat $\mathrm{H}$. Reliability and validity of health status measurement by the TAPQOL. Arch Dis Child 2005; 90: 351-8.

http://dx.doi.org/10.1136/adc.2003.048645

[24] Bayley N. Manual for the Bayley Scales of Infant Development 2rd ed. San Antonio, TX: The Psychological Corporation 1993.

[25] Achenbach, Manual for the child behavior checklist 4-18 and 1991 profile. University of Vermont. Department of Psychiatry, Burlington 1991

[26] Groot de A, Koot HM, Verhulst FC. Cross-cultural generalizability of the child behavior checklist cross-informant syndromes. Psychol Assess 1994; 6: 225-30. http://dx.doi.org/10.1037/1040-3590.6.3.225

[27] Dekker MC, Koot HM, van der Ende J, Verhulst FC. Emotional and behavioral problems in children and adolescents with and without intellectual disability. J Child Psychol Psychiatry 2002; 43: 1087-98. http://dx.doi.org/10.1111/1469-7610.00235

[28] Weijerman ME, van Furth AM, van der Mooren MD, et al. Prevalence of congenital heart defects and persistent pulmonary hypertension of the neonate with Down syndrome. Eur J Pediatr 2010; 169: 1195-9. http://dx.doi.org/10.1007/s00431-010-1200-0

[29] Schieve LA, Boulet SL, Kogan MD, Van Naarden-Braun K, Boyle CA. A population-based assessment of the health, functional status, and consequent family impact among 
children with Down syndrome. Disabil Health J 2011; 4: 68-77.

http://dx.doi.org/10.1016/j.dhjo.2010.06.001

[30] Weijerman ME, Brand PL, Furth van AM, Broers CJ, Gemke RJ. Recurrent wheeze in children with Down syndrome: is it asthma? Acta Paediatr 2011; 10: e194-7. http://dx.doi.org/10.1111/j.1651-2227.2011.02367.x

[31] Bloemers BL, van Furth AM, Weijerman ME, et al. High incidence of recurrent wheeze in children with Down syndrome with and without previous respiratory syncytial virus lower respiratory tract infection. Pediatr Infect Dis $\mathrm{J}$ 2010; 29: 39-42. http://dx.doi.org/10.1097/INF.0b013e3181b34e52

[32] McDowell KM, Craven DI. Pulmonary complications of Down syndrome during childhood. J Pediatr 2011; 158: 319-25. http://dx.doi.org/10.1016/j.jpeds.2010.07.023
[33] Verstegen $\mathrm{RH} 1$, van Gameren-Oosterom HB, Fekkes M, Dusseldorp E, de Vries E, van Wouwe JP. Significant impact of recurrent respiratory tract infections in children with Down syndrome. Child Care, Health and Development 2013; 39: 801-9.

[34] Eisenhower AS, Baker BL, Blacher J. Preschool children with intellectual disability: syndrome specificity, behaviour problems, and maternal well-being. J Intellect Disabil Res 2005; 49: 657-71. http://dx.doi.org/10.1111/j.1365-2788.2005.00699.x

[35] Veek van der SM, Kraaij V, Garnefski N. Down or up? Explaining positive and negative emotions in parents of children with Down's syndrome: goals, cognitive coping, and resources. J Intellect Disabil Res 2009; 34: 216-29. http://dx.doi.org/10.1080/13668250903093133

DOI: http://dx.doi.org/10.6000/2292-2598.2014.02.01.2

(C) 2014 Weijerman et al.; Licensee Lifescience Global.

This is an open access article licensed under the terms of the Creative Commons Attribution Non-Commercial License (http://creativecommons.org/licenses/by-nc/3.0/) which permits unrestricted, non-commercial use, distribution and reproduction in any medium, provided the work is properly cited. 